\title{
Nacionalismo y conciencia racial en los escritos de Luis Felipe Dessús: el viaje de un afro- puertorriqueño hacia la liberación
}

\author{
Nationalism and Racial Awareness in the Writings of Luis Felipe \\ Dessus: An Afro-Puerto Rican's Journey Toward Liberation \\ Nacionalismo e consciência racial nos escritos de Luis Felipe Dessus: \\ a viagem de um afro-porto-riquenho para a libertação
}

\section{Laurence E. Prescott}

\section{PENNSYLVANIA STATE UNIVERSITY, ESTADOS UNIDOS}

Profesor Emérito del Departmento de Español, Italiano y Portugués de

Pennsylvania State University. PhD en Español de Indiana University, Bloomington. Autor de Candelario Obeso y la iniciación de la poesía negra en Colombia (Instituto Caro y Cuervo, 1985) y Without Hatreds or Fears: Forge Artel and the Struggle for Black Literary Expression in Colombia (Wayne State University Press, 2000), con el que obtuvo el Magazine 2001 Outstanding Academic Title Award. Co-fundador de Afro-Latin/American Research Association (ALARA). Autor de múltiples artículos en revistas especializadas. Correo electrónico: lep4@psu.edu

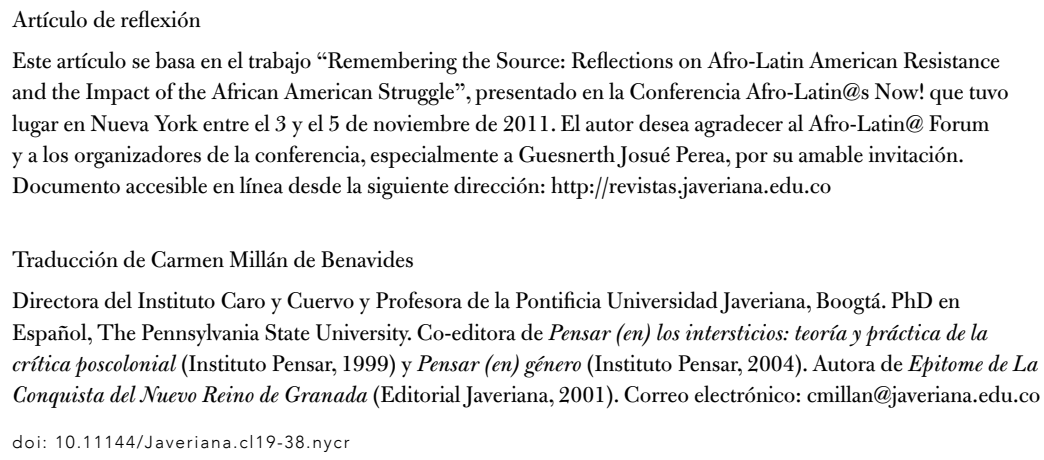




\section{Resumen}

El presente artículo rescata la obra de Luis Felipe Dessús, poeta, ensayista y periodista afropuertorriqueño del temprano siglo XX, invisibilizado y discriminado como tantos otros escritores afrodescendientes en el campo literario de la isla. La polémica voz de Dessús, inscribe en registro afroantillano fuertes cuestionamientos al reordenamiento neocolonial de Puerto Rico, en el cual persistían los antiguos privilegios, mucho después de la abolición de la esclavitud en el tardío siglo XIX. Su conciencia racial y social enfrentó arraigados prejuicios étnicos y fuertes naturalizaciones sociales del statu quo puertorriqueño y su vocación diaspórica lo solidarizó con la lucha internacional de los afrodescendientes, incluidos los Afroamericanos de los Estados Unidos.

Palabras clave: afroamericanos, Luis Felipe Dessús, Puerto Rico, slavery raza, esclavitud

\section{Abstract}

This essay redeems the works of Luis Felipe Dessús, AfroPuertorican poet, essayist, and journalist of the early XX century, who, similarly to many other Afro-descending writers, was discriminated and denied visibility in the literary field of the island. The controversial voice of Dessús engraves in Afro-Antillean words strong questionings to the neocolonial rearrangement of Puerto Rico, which kept old privileges alive long after the abolition of slavery in the late XIX century. His racial and social awareness faced deeply rooted ethnic prejudices and strong social naturalizations of the Puerto Rican statu quo. Also, his diaspora vocation showed his solidarity with the international struggle of Afrodescendants, including AfroAmericans in the United States. Keywords: Afro-Americans; Luis Felipe Dessús; Puerto Rico; race;

\section{Resumo}

$\mathrm{O}$ presente artigo visa resgatar a obra de Luis Felipe Dessús, poeta, ensaísta e jornalista afro-porto-riquenho de inícios do século XX, invisibilizado e discriminado como já tantos outros escritores afrodescendentes no campo literário da ilha. A voz polêmica de Dessús inscreve no registo afro-antilhano fortes questionamentos para o reordenamento neocolonial de Porto Rico, no que persistiram os antigos privilégios, muito depois da abolição da escravatura nos finais do século XIX. Sua consciência racial e social enfrentou arraigados preconceitos étnicos e fortes naturalizações sociais do status quo portoriquenho e sua vocação de diáspora solidarizou-o com a luta internacional dos afrodescendentes, incluso os Afro-americanos dos Estados Unidos.

Palavras-chave: afro-americanos; Luis Felipe Dessús; Porto Rico; raça; escravatura 


\begin{abstract}
"El murmullo de la crítica proveniente de sanos opositores es algo peligroso. Lleva a algunos de los mejores críticos a un silencio desafortunado, a una parálisis, y a otros a un discurso apasionado e intemperante que provoca la pérdida de audiencia.

La crítica honesta y aguda proveniente de quienes ven afectados sus intereses por ella -la crítica hecha a los autores por parte de sus lectores, del gobierno por los gobernados, de los líderes por sus seguidores- es el corazón de la democracia y garantiza la salvaguarda de las sociedades modernas". W. E. B. DU BOIS, LAS ALMAS DE LA GENTE NEGRA (1903)
\end{abstract}

DESDE 1970 LOS investigadores que se ocupan de la literatura de América Latina han venido fijando su atención en el estudio de autores afrodescendientes cuyas vidas y obras habían venido siendo pasadas por alto, infravaloradas u olvidadas por la crítica convencional en sus propios países.

Gracias al estímulo proveniente a veces del orgullo nacional o de sentimientos de orgullo racial, y animados por el ejemplo y el interés de investigadores y estudiantes de los Estados Unidos, Europa y otros lugares, investigadores y estudiantes de Colombia, Uruguay, Perú, Ecuador, Costa Rica, Panamá, Argentina y otros países, han posado su mirada en la obra de autores muchas veces considerados "menores" o que han sido relegados al anonimato. Entre aquellos que han sido "redescubiertos" tenemos autores que han sido objeto de libros, tesis doctorales, tesinas de maestría y, en muchos casos, reimpresiones. Tal es el caso de los colombianos Candelario Obeso (1849-1884), Jorge Artel (1909-1994), Hugo Salazar Valdés (1926-1998) y Teresa Martínez Arce de Varela (1913-1998)2 , los panameños Federico

1 The Souls of Black Folk en traducción de Rubén Casado y Francisco Cabrera fue publicado con el título Las almas del pueblo negro. En el mismo sentido la selección bilingüe hecha por Jesús Benito Sánchez y Ana María Manzanas.

2 En 2008 la Fundación Color de Colombia y Múnera Editores publicaron la muy interesante Colección Presencia Afrocolombiana, que consta de seis obras previamente publicadas por autores de los siglos XIX y XX: Juan Coronel (1868-1904), Francisco Botero (1885-1938), Manuel Baena (1888-19??), Rogerio Velásquez (1908-1965), Carlos Arturo Truque (19271970), y Eugenio Darío (Ca. 1940s-1950s). Dos años más tarde el Ministerio de Cultura de Colombia publicó la Biblioteca de Literatura Afrocolombiana, una impresionante colección de diecinueve libros de poesía, narrativa, teatro, ensayo y literatura de tradición, con obras de quince autores afrodescendientes, nacidos en los siglos XIX y XX. Esta Biblioteca es muestra de la diversidad y cobertura geográfica que ha tenido la producción de autores afrodescendientes. Autores como Candelario Obeso, Jorge Artel y Hugo Salazar Valdés, cuentan con su propio volumen. Martínez Arce aparece en la notable Antología de mujeres poetas afrocolombianas que conforma el volumen 16, el cual incluye 58 autoras. En honor a la verdad (2009), una biografía 
Escobar (1861-1912) y Gaspar Octavio Hernández (1893-1918)3 ; y los uruguayos Pilar Barrios (1889-1974) y Virginia Brindis de Salas (1908-1958).

Los poetas y escritores de ascendencia africana también han poblado el paisaje literario de Puerto Rico. Sin embargo, ellos también han sido ignorados, olvidados y considerados como escritores de menor valía que sus colegas blancos. En efecto, hasta fecha reciente los escritores afro-puertorriqueños han sido invisibilizados en la literatura puertorriqueña ${ }^{5}$. Tal como ocurre en otros países hispanoamericanos, la vergüenza asociada a la identidad negra, el desdén por la herencia africana y el culto al blanqueamiento han contribuido a la ignorancia y a la falta de interés por los escritores negros de Puerto Rico. Acosta-Belén y Santiago señalan:

[La herencia africana] fue esencialmente subestimada en las narrativas históricas del Siglo XIX [...]. Las élites intelectuales y políticas europeizantes, no consideraban que la herencia africana era un componente significativo para definir a la naciente nación puertorriqueña. (16)

y selección de obra poética de Martínez Arce compilada por Úrsula Mena de Lozano y Ana Rosa Herrera Campillo, ha puesto a disposición del público obras adicionales. También en 2010, con el título Si yo fuera tambó, la profesora Graciela Maglia preparó una edición crítica de poesía de Obeso y Artel. En "Contribution to a Bibliography of Afro-Colombian Writers", que se publicará en Negritud, Revista de Estudios Afro-Latinoamericanos, incluyo un listado de publicaciones recientes.

3 Gracias a la dedicación de su hijo, buena parte de los escritos del poeta Gaspar Octavio Hernández fue reimpresa en 1966 (Obras selectas). Jackson (Black Image; Black Writers) ayudó al conocimiento del poeta, ganando para él un reconocimiento más allá de las fronteras panameñas. Aunque los escritos de Federico Escobar no han vuelto a ser publicados en un libro, referencias críticas a su obra en "Nationalist Rhetoric and Suppression of Negritude: Literary Whiteness in Poems by Federico Escobar and Gaspar Octavio Hernández" de Sonja Stephenson Watson y "Negro nacî" de Laurence Prescott, han arrojado luz sobre sus actividades literarias.

4 Mientras Pregón de Marimorena (1947) y Cien cárceles de amor (1949), los dos libros de poemas de Virginia Brindis de Salas, eran conocidos entre la población negra del Uruguay, parecen haber permanecido ignorados por el resto de la población. Jackson (Black Image), Lemuel Johnson, Carroll M. Young y Marvin A. Lewis han contribuido en gran medida para lograr que el trabajo de Brindis de Salas sea conocido y apreciado.

5 En su muy útil Diccionario de Literatura Puertorriqueña (1955; 2a ed., 2 vols., 1974, 1979), Josefina Rivera de Álvarez no especifica la identidad racial de los autores. En consecuencia, es difícil saber quiénes tienen ascendencia africana. Ocasionalmente (o quizá eufemísticamente) aparece el dato "Hijo de familia humilde y de escasos medios económicos" (300) o "De orígenes humildes" (487), para referirse a dos autores negros: Tomás Carrión Maduro y Eleuterio Derkes. Estos datos podrían indicar la procedencia racial de los mencionados autores. 
Para los intelectuales criollos del Siglo XIX, la base de la cultura y del rostro de Puerto Rico era el componente español, es decir europeo. De acuerdo con Zilkia Janer:

El periodo temprano de la construcción de nación estuvo caracterizado por un elocuente silencio en torno al componente africano de la cultura y la sociedad de Puerto Rico [...]. La nación a la que aspiraban los criollos del periodo era fundamentalmente española y no tenía en cuenta la diversidad étnica. $(12)^{6}$

Debe también recordarse que, a diferencia de otras posesiones españolas en las Américas, tanto Puerto Rico como Cuba solo ganaron su independencia política de la Madre Patria hasta el fin del Siglo XIX, como resultado de la Guerra Cubano - Hispano - Americana de 1898. Luego de la toma de la isla por los Estados Unidos en 1898, muchos líderes puertorriqueños tanto blancos como negros, pensaron que los problemas raciales prácticamente no existían en la isla y se mantuvieron firmes en la idea de una "gran familia puertorriqueña" (Janer 18) controlada por los hombres criollos y caracterizada por la desigualdad social. Al hacer esto, no solo se apegaron al legado hispánico sino que también intentaron demostrar a los Estados Unidos que Puerto Rico les era igual -si no superior-en el tratamiento de las minorías raciales. Tal como señala Ileana M. Rodríguez-Silva existía "la noción de que los problemas de división y explotación raciales habían sido erradicados con la abolición de la esclavitud y el mito acompañante según el cual la sociedad puertorriqueña era el ejemplo más palpable de la armonía racial" (149). Para mantener dichas creencias y promover la unidad nacional y al mismo tiempo proyectar la imagen de una sociedad racialmente armónica, los líderes de las élites consideraron necesario el silenciamiento de las voces discordantes y la supresión de los discursos subversivos ${ }^{7}$.

Un autor que, negándose a ser silenciado, resistió y desafió al nuevo orden imperial y el pensamiento nacionalista y racial del momento que sutil o abiertamente borraba a las negritudes y aminoraba la importancia de la cultura negra

6 Para Roberto Ramos Perea, la producción literaria temprana de negros y mulatos fue "desdeñada por razón del color de piel de sus autores" (7).

7 En su importante libro Silencing Race: Disentangling Blackness, Colonialism, and National Identities in Puerto Rico, Rodríguez-Silva entiende, descubre y explica la miríada de hilos y nudos de raza, color, clase y política que permearon la unidad nacional e ignoraron voces que matizaban la afirmación de unidad y disputaban la pretendida armonía racial del Puerto Rico post guerra del 98. Véase también Negrón-Portillo "Surviving Colonialism and Nationalism". 
fue Luis Felipe Dessús ${ }^{8}$. Por esta única razón tanto él como sus escritos ameritan cuidadosa investigación. Periodista combativo, comentarista político y poeta de gran sensibilidad, Dessús defendió la independencia política de Puerto Rico, colaboró en periódicos, revistas, guiones y revistas literarias, que criticaban la presencia de los Estados Unidos en la isla y con poemas que mostraban el orgullo racial y evidenciaban el prejuicio racial de la sociedad y la cultura puertorriqueñas. Adicionalmente, en 1916 publicó un libro de poesía y prosa llamado Flores y balas (estados de alma), editó y colaboró en el volumen El Álbum de Guayama (1918), dedicado a los intereses comerciales y a los creadores literarios de dicha ciudad, y fundó y editó la revista literaria y política Pancho Ibero (1917-1920).

Sin embargo, y quizá por las posiciones y acciones políticas de Dessús, poco o casi nada parece haber sido escrito sobre él ${ }^{9}$. No obstante, los poemas a él dedicados por al menos tres de sus contemporáneos (incluido el joven Luis Palés Matos), pueden dar testimonio de su importancia, talento y del respeto que despertaba $^{10}$. Con base en las investigaciones llevadas a cabo tanto en Puerto Rico

8 Mi interés y el conocimiento de la existencia de Luis Felipe Dessús y de la de otros escritores puertorriqueños se inició durante mis estudios graduados al finalizar la década de los sesenta y al principio de los setenta, cuando leí Problemas sociales. El negro: Haití-Estados Unidos-Puerto Rico (1940), el estudio de José Rosario Colomban y Justina Carrión. Más tarde, cuando me encontraba investigando sobre los viajes y publicaciones del escritor afrocolombiano Juan Coronel (1868-1904) en la biblioteca de la Universidad de Puerto Rico, Recinto de Río Piedras, me familiaricé con El álbum de Guayama (1918) y renové mi interés en Flores y balas (estados de alma) (1916), que había consultado previamente en el Schomburg Center, en Nueva York. Investigaciones realizadas a través de Internet en 2011 condujeron al descubrimiento de la importante revista Pancho Ibero (1917-1920) y otras publicaciones que, eventualmente, tuve la suerte de localizar y examinar, a menudo a través de microfilms. Sin embargo, tal como señala el profesor Ramos Perea, las copias de la revista no están completas. Sin embargo, las copias existentes contienen la mayor parte del material de y sobre Dessús, permitiendo así al lector conocer la trayectoria de sus ideas y las posibles fuentes que influyeron sobre su obra.

9 El único artículo sobre el trabajo de Dessús escrito por alguno de sus contemporáneos parece ser la reseña de su libro por el crítico Enrique Lefebre, titulada "Estudios críticos. Luis F. Dessús: Flores y balas" publicada en Puerto Rico Ilustrado (Número 350, 6 enero 1917). Aunque las obras de Dessús han sido incluidas en antologías de poesía puertorriqueña desde las primeras décadas del siglo XX -véanse por ejemplo, Carreras (103-104); Torres Rivera, Gómez Tejera, Losada y Porras- el conocimiento e interés de los investigadores en su obra en prosa es algo apenas reciente y creciente. Después de la publicación del libro de Narciso descubre su trasero; el negro en la cultura puertorriqueña de Zenón Cruz, que comenta poemas de Dessús, tal vez sea Eileen J. Suárez Findlay la primera investigadora en llamar la atención sobre la importancia de la obra en prosa de Dessús.

10 Véanse los sonetos "Guayama" de Luis Lloréns Torres (1887-1945), natural también de Juana Díaz, incluidos en sus Sonetos sinfónicos (1914); "Melancolía" de Luis Palés Matos (18981959), incluido en Azaleas (1915), su primer libro; y "Flores y balas" de Guillermo Atiles 
como en los Estados Unidos, este artículo examina algunos de los escritos en prosa de Dessús a fin de develar el pensamiento sobre nacionalismo y conciencia racial de un poco conocido pero importante intelectual negro puertorriqueño, quien trató estos temas durante toda su vida periodística. Un corto análisis del contenido y contexto de sus escritos puede ayudar para aclarar aspectos importantes de asuntos relacionados con las actividades del mundo literario e intelectual de Afro-Puerto Rico durante las primeras décadas del siglo XX y quizá pueda contribuir a la comprensión del cada vez más intenso discurso de Dessús y a su compromiso emergente con las luchas internacionales de las gentes de la diáspora africana (incluidas las de los Estados Unidos) por la justicia y la liberación.

Antes de continuar, sería útil definir brevemente dos términos que serán empleados en este ensayo. Cuando se habla de nacionalismo nos referimos al "apoyo de ideas y movimientos políticos que proclaman el derecho de una nación a la independencia y al auto-gobierno" según la definición del Penguin Dictionary of Nineteenth-Century History (Belchem y Price 407), y también a "una actitud de lealtad y orgullo hacia la propia nación" tal como señala Eugene J. McCarthy (106). Benedict Anderson ha dado una definición que ha sido plenamente aceptada, según la cual una nación es "una comunidad política imaginada como inherentemente delimitada y soberana" (23). Su afirmación según la cual "la palabra impresa es la que inventa la nación" pues posee una "capacidad para generar comunidades imaginadas al construir, de hecho, solidaridades particulares" es especialmente relevante para el asunto de este ensayo. Tal como nos recuerda Benedict Anderson

[...] una nación inspira amor, y muchas veces amor y auto-sacrificio. Los productos culturales del nacionalismo - poesía, prosa, música, artes plásticasmuestran dicho amor de forma clara en muchas formas y estilos [...] (141-200)

Tal como pretendo demostrar, los escritos de Luis Felipe Dessús también reflejan amor por su país y muestran su apoyo por el autogobierno y la

García (1882-1955) de Ponce, publicado en Cien sonetos (Ponce, 1925) y reproducido por Zenón Cruz en Narciso descubre su trasero (359-360). "Guayama" se refiere al pueblo en el que Dessús vivió y trabajó y en el cual Palés Matos nació; "Flores y balas" se refiere al título del libro de poesía y prosa de Desssús, ya mencionado. También debe citarse la mención que de Dessús hace el activista y escritor afro- puertorriqueño Joaquín Colón López, quien emigró a Nueva York en 1917. Colón López (1896-1964) incluye a Dessús entre los más destacados intelectuales negros de la Isla y señala que ellos fueron "hombres cultos por amor a la cultura, no cultos por oficio, y por ende pensaban con libertad, sin temor [...]. Las más de las veces su educación la adquirieron por esfuerzos propios; no se debían a nadie, como no fuera a los esfuerzos de su humildes padres" (29-30). 
independencia. Adicionalmente, sus escritos exudan y evidencian una fuerte conciencia racial, esto es, un reconocimiento no solo de las diferencias físicas que lo identifican como un hombre negro y lo distinguen de un blanco o un mulato, sino también de los significados culturales tácitos e implicaciones sutiles que la sociedad asocia con la identidad negra: origen esclavo, trabajo degradante, falta de inteligencia, fealdad. La percepción por Dessús tanto de las normas y valores sociales y culturales que ponían en duda las capacidades de los afro-puertorriqueños, como de las tradiciones y el liderazgo políticos que minimizaban sus preocupaciones e intentaban silenciar sus voces, hicieron que Dessús fortaleciera su nacionalismo y lo llevaron a pregonar su orgullo racial, manifestando su negritud, develando y resistiendo el discurso racista y expandiendo su visión más allá de Puerto Rico para criticar la filosofía de un problemático líder afro-americano y afirmando la humanidad de la gente negra. En cuanto a eso, Dessús parece prefigurar lo que escribiría décadas después el psiquiatra e intelectual anti-colonialista Frantz Fanon en Piel negra, máscaras blancas: "Decidí, ya que resultaba imposible para mí separarme de un complejo innato, afirmarme como un Hombre negro. Como el otro dudaba en reconocerme, solo me quedaba un camino: hacerme conocer" (115 énfasis en el original).

De acuerdo con las fuentes disponibles, Dessús nació en 1875 (dos años después de que España aboliera la esclavitud en la Isla) en Juana Díaz, una localidad situada en la zona de producción azucarera de la costa sur de Puerto Rico. Murió 45 años después en Ponce, en diciembre de 1920. No disponemos de mayor información acerca de su familia de origen o de su vida en los años previos a 1920. De acuerdo con Josefina Rivera de Álvarez, Dessús hizo estudios de primaria, pero después adquirió sus conocimientos de forma autodidacta. Sin embargo, una noticia de 1920 acerca de la nominación de Dessús para la Cámara de Representantes de Puerto Rico afirma que recibió en París "dos títulos académicos, con medalla de oro" ${ }^{\prime 1}$. Rivera de Álvarez señala que Dessús colaboró con varios medios periódicos (¿publicaciones periódicas?) de Puerto Rico luego de que la isla cayera bajo el control de los Estados Unidos como resultado de la Guerra Cubano - Hispano - Americana de $1898^{12}$.

11 Véase la revista Pancho Ibero del 11 de septiembre de 1920 (10).

12 Rivera de Álvarez parece haber tomado esta información del estudio de Antonio S. Pedreira $E l$ periodismo en Puerto Rico (1941), póstumamente publicado. Aunque Pedreira no menciona a Dessús o su trabajo en ninguno de los once capítulos del libro, sí lo hace en el largo listado "Orden alfabético de periódicos" (387-558) que cierra el libro. Menciona la revista Pancho Ibero (502) y las colaboraciones de Dessús para los diversos medios periódicos que Rivera 
La publicación en prosa más temprana de Dessús de la que se tiene noticia es el artículo "El cinismo de ayer", que escribió en el número del 3 de mayo de 1901 de La fusticia, un periódico de orientación obrera que se publicaba en Ponce $^{13}$. En su breve pero agudo comentario, Dessús acusaba a los dirigentes del Partido Republicano de Puerto Rico de sistemáticamente excluir a la gente común y corriente de la participación en los procesos de decisión para elegir a los miembros del comité que elegiría a la Cámara de Delegados a fin de imponer a su propio candidato. Dessús culpó al Partido de financiar dicho comité, lo que en su opinión, vulneraba la soberanía popular, algo que Dessús atribuía a "cuatro imbéciles pretensiosos [sic]" a quienes no mencionaba. Señalaba, sin embargo, que Tomás Carrión Maduro, a quien los trabajadores y él mismo apoyaban como el mejor candidato para representar al pueblo "de abajo", no fue considerado en razón a su origen racial: "al decir de ellos, era un negro que iba a nublar la Cámara" (énfasis en el original) ${ }^{14}$.

La denuncia inequívoca de discriminación racial realizada por Dessús no terminaba allí. Señalaba que otro escritor (Ponce de León) había estado publicando en el periódico republicano La Opinión una serie de "siluetas" que se enfocaban en los méritos políticos de algunos hombres distinguidos, todos ellos blancos. Cuando Dessús inició en el mismo periódico una serie titulada "Tipos populares" que presentaba a tres negros ${ }^{15}$, el comité ordenó la suspensión de su publicación aduciendo que se trataba de "propaganda

de Álvarez cita. Investigaciones recientes muestran que Dessús también colaboró con otras publicaciones como El Criterio Libre (1900), La fusticia (1901) y The Puerto Rico Eagle (1903), "Órgano del Partido Republicano Puertorriqueño". De acuerdo con Edgar Martínez Masdeu, Dessús también colaboró en la revista modernista El Carnaval (1899-1911) de San Juan (147).

13 Véase Eileen J. Suárez Findlay (266 n23). Pedreira proporciona información básica sobre el periódico en El periodismo en Puerto Rico (473).

14 Un insulto similar fue aplicado al político y hombre de Estado afrocolombiano Luis A. Robles (1849-1899) quien representó al Partido Liberal en el Congreso de la República. Véase Raúl Porto del Portillo. Véase también Narciso descubre su trasero de Zenón Cruz que recoge frases similares que ridiculizan la entrada de una persona negra en una asamblea de blancos.

15 Las tres personas que se presentaban eran José N[emesio] Acosta, Antonio Guilbe y Cosme Díaz. El primero era un periodista, autor de un poemario llamado Propios y extraños relacionado por Antonio S. Pedreira, pero del cual no se sabe su fecha de publicación (518). Acosta fue una de las dos personas a quienes en 1907, Dessús dedicó su poema "Gotas de sangre" (Flores y balas 39), que escribió cuando se hallaba encarcelado. Guilbe era un trabajador quien, de acuerdo con Mariano Negrón-Portillo, "fue líder de varios de los ruidosos grupos marginales de Ponce" que, "junto con algunos de sus seguidores recorría las calles, armado, con la bandera de los Estados Unidos sobre sus hombros, burlándose de la élite" ("Surviving Colonialism and Nationalism"43). No ha sido posible encontrar información sobre Díaz. 
de razas" que podía llevar a "la desmembración del partido" o, como señaló Dessús irónicamente, "la caída horrible del imperio republicano". Al yuxtaponer las dos series y contrastar la reacción producida o la carencia de la misma, Dessús agudamente cuestionaba la asumida norma de blancura de la sociedad puertorriqueña, a la vez que rechazaba la pretendida neutralidad de la identidad blanca ${ }^{16}$. Al mismo tiempo, el muy políticamente astuto periodista también se ocupó de aquellas personas de su misma raza que aceptaban las actuaciones del partido, advirtiendo que con ese proceder ellos "[sancionan] un procedimiento de absorción y preterición de aquellos y prestan su decidido concurso para su eterna vergüenza". Es decir que para Dessús todos aquellos negros obedientes, que se comportaban como si aún se viviera bajo el régimen de esclavitud, estaban reviviendo el dicho popular "Branco levanta foete, negro boca abajo", con el cual terminaba su comentario.

Dessús trataba sin ambages asuntos relacionados con política, raza y soberanía popular y ello lo caracterizaría durante toda su carrera como escritor. "El déspota yanki. Tres pueblos bajo la tiranía de un mentecato", un artículo que publicó bajo el pseudónimo de Marat en The Puerto Rico Eagle en diciembre de 1903 es un claro ejemplo de su perseverante estilo. En este ensayo de opinión, Dessús denunciaba a W. S. Eckman, Inspector de Educación de las poblaciones de Juana Díaz, Santa Isabel y Coamo por abuso de autoridad y pedía al Comisionado de Educación la destitución del funcionario. Dessús acusó a Eckman, un estadounidense, de inmiscuirse "con actitud despótica" en los asuntos de la alcaldía, el concejo municipal y la junta de educación. Atribuía dichas conductas a la ignorancia de Eckman y sus ambiciones de convertirse en mandatario de "ciudadanos honrados". Poniendo el problema en la terminología política local, Dessús calificaba a Eckman como "un federal apasionado" en medio de un distrito eminentemente republicano, sugiriendo que el funcionario contaba con el apoyo del partido político rival ${ }^{17}$.

16 Citando un artículo de Ann Phoenix, Steve Garner escribe en Whiteness; an Introduction: "La blancura de la piel se ha convertido en la manera normal y universal en la que nos representamos como humanos: 'los blancos no son de cierta raza, ellos son simplemente, la raza humana' [...]. Ser blanco es parte constitutiva de ser humano". Así, como señala Garner "el primer esfuerzo que deben emprender los grupos dominados es el de transformar esta estrategia ideológica de doxa (los límites del sentido común) a ortodoxia (la elección de una alternativa sobre otra y el reconocimiento de la existencia de alternativas") (34-35, énfasis en el original).

17 La denominación federal se refiere al Partido Federal, fundado en 1899, dirigido por Luis Muñoz Rivera. Este partido tuvo muy corta vida; había sido el Partido Liberal y, eventualmente se unió al Partido Unión. El Partido Liberal había surgido del ala fusionista del Partido Autonomista. 
Ya era bastante malo, Dessús insinuaba que la educación de los residentes de los tres municipios fuera controlada por un extranjero, "un yanki", representante del gobierno de los Estados Unidos, pero el hecho de que el funcionario fuese pagado con el dinero de los habitantes de esos municipios, precisamente las personas a las que él irrespetaba y a las que se oponía, ya era el colmo. Dessús se oponía a lo que él percibía como un tratamiento dictatorial y grosero de la gente por parte de Eckman, por lo que llamaba al funcionario "mentecato", "advenedizo" y "tipejo." Aunque Dessús no identificaba conductas específicas de Eckman reflejadas en edictos o actuaciones que lo llevaran al empleo de esos calificativos, el artículo de Pablo Navarro-Rivera "The Imperial Enterprise and Educational Policies in Colonial Puerto Rico", puede ilustrar mejor lo que preocupaba a Dessús. Tal como señala Navarro Rivera, después de tomar posesión de Puerto Rico, el gobierno de los Estados Unidos estableció tanto un "muy centralizado gobierno civil" bajo su directo control, como un

[...] igualmente centralizado sistema educativo dirigido por un comisionado de educación nombrado por el presidente de los Estados Unidos. Educar al pueblo del recientemente adquirido territorio era parte de la labor "civilizatoria', de la misión americanizadora o asimilacionista diseñada para demoler o pulverizar los elementos culturales constitutivos de los conquistados. (164)

Es muy posible que la conducta "dictatorial" de Eckman reflejara e implementara la mencionada misión, con la cual Dessús, sin duda, no estaba de acuerdo. De allí que para Dessús era obvio que "[l]a suspensión de Eckman se impone"18.

Hacia el final de su artículo Dessús señalaba que la falta de respuesta gubernamental a las justas demandas populares podría acarrear "terribles hecatombes". Esta amenaza velada no podía pasar desapercibida por las autoridades. Repitiendo la solicitud de destitución, Dessús finalizaba su artículo declarando que la educación pública merecía una representación más honesta que la de Eckman y que el Departamento de Educación merecía un delegado

El término republicano remite al Partido Republicano, también fundado en 1899 y dirigido por José Celso Barbosa. Este partido había salido del ala ortodoxa del Partido Autonomista. Aunque rivales, los dos partidos favorecían la anexión a los Estados Unidos. Véase el trabajo de Grosfoguel para mayor ilustración sobre las posiciones de los dos partidos (60-63) e Ileana M. Rodriguez-Silva, Silencing Race (132-134).

18 Es interesante señalar que Dessús escogió la expresión Yankee, un insulto incendiario, en vez del gentilicio americano en el título de su artículo. Sin embargo, no empleó la grafía yanqui, tal como José Martí y otros habían hecho y que era la corrientemente empleada. El escribir la palabra con "k" (yanki) pudo haber sido una alusión muy sutil a las actividades del Ku Klux Klan en los Estados Unidos, famosas por su violencia contra la gente negra. 
más calificado y más refinado que el que en ese momento tenía. Los materiales de archivo que se conservan, no dan cuenta de si Eckman permaneció en su puesto o fue removido del mismo. Lo que sí muestran es que él demandó a Dessús por difamación y que un año y medio más tarde, el 31 de mayo de 1905 , la Corte Suprema de Puerto Rico falló en favor del demandante y condenó al periodista a seis meses de prisión ${ }^{19}$.

Las notas que acompañan el poema de Dessús titulado "Gotas de sangre" señalan que los esfuerzos hechos por Dessús para obtener el perdón del gobernador Beckman Winthrop o para lograr que la pena fuera ignorada, no tuvieron éxito ${ }^{20}$. Otros poemas y piezas en prosa publicados en el libro Flores y balas (estados de alma) ${ }^{21}$ y todas las publicaciones con fecha de 1907, tienen la inscripción "Cárcel de Arecibo", por lo que se sabe que Dessús pagó su condena en la cárcel de esa población. En el prólogo de su libro Dessús identificaba las causas de su condena en "La corrupción del gobierno; las venalidades de una policía sobornada; las intransigencias de un juez histérico, cuya faz estúpida lo caracterizaba como un verdadero inquisidor; y el medio social en complicidad torpe y absurda" (10). Los esfuerzos para silenciar al escritor, sin embargo, no tuvieron efecto alguno. De hecho, en las semanas posteriores a la publicación de "El déspota yanki" Dessús continuó levantando su voz contra los individuos, instituciones, actitudes, creencias y proyectos que consideraba anti progresistas y dañinos para el pueblo de Puerto Rico.

19 Véase Colección de las sentencias y resoluciones dictadas por el Tribunal Supremo de Puerto Rico vol. 8 (1906): 486-489 y 491.

20 Los cargos contra Dessús y la condena subsiguiente no eran asunto raro en aquella época para los periodistas críticos del nuevo régimen colonial.José (Che) Paralitici señala en "Imprisonment and Colonial Domination, 1898-1958" que el gobernador militar emitió un decreto en 1898, mediante el cual limitaba la libertad de prensa, expresamente desautorizando la publicación de artículos que criticaran a las autoridades o que fueran incendiarios (68). Varios periodistas reconocidos fueron víctima del decreto. Por ejemplo, Julio Medina González "fue acusado y condenado a siete años de prisión" por publicar una caricatura contra el gobernador Winthrop en un número de la publicación La Independencia (1905) que salía dos veces por semana en Mayagüez. "Medina pagó año y medio de su sentencia, la cual fue conmutada por el mismo gobernador Winthrop" (69). De acuerdo con Adalberto López, en 1899 "Todos los periódicos que se publicaban en Puerto Rico [estaban] bajo el control directo del gobierno militar estadounidense de Puerto Rico (484).

21 Luis Felipe Dessús. Flores y balas (estados de alma). Guayama, P.R.: Tip. Unión Guayamesa, 1916. La copia del libro que se halla en la colección del Schomburg Center tiene la siguiente inscripción: "A la biblioteca mnpl de New York. Obsequio de El Autor, Febrero 12 de 1917 Guayama, P.R." La Crisis, publicación de NAACP, acusaba recibo del libro, en mayo de 1918. 
En otro artículo llamado "La próxima emigración" que también apareció en la columna "Comentando" en The Puerto Rico Eagle tan solo ocho días después de la publicación de "El déspota yanki", Dessús protestaba enérgicamente contra la nueva ola de reclutamiento de trabajadores puertorriqueños para laborar en tierras remotas $^{22}$. La primera de esas migraciones había ocurrido dos años atrás (19001901) cuando grupos de hombres, mujeres y niños viajaron a Hawaii, por entonces territorio recientemente adquirido por los Estados Unidos, para trabajar en las plantaciones de caña ${ }^{23}$. Al recordar anteriores migraciones de puertorriqueños a México, Daiquiri (Cuba) y Hawaii, Dessús las comparaba con el nuevo esquema que él consideraba una empresa maligna que recordaba el tráfico de esclavos ("la venta del hombre por el hombre"). Pensaba que la emigración traía inseguridad tanto para el migrante como para la familia que dejaba atrás ya que no había "garantía alguna de salud, libertad o futuro" para el trabajador. Dessús pedía a quienes pensaban en migrar tener en cuenta las tristes experiencias de quienes los habían antecedido, quienes habían sudado trabajando en otras tierras sin recibir una justa compensación. Aquellos que engatusaban a los trabajadores con promesas de mejores oportunidades e ingresos carecían de "todo sentimiento humano, todo espíritu de fraternidad, todo deber de patriotismo, toda protesta de su propia conciencia, por un puñado de oro".

Dessús también señalaba que los reportes de prensa propagados por la prensa opuesta al gobierno en los que se daba cuenta de la hambruna generalizada eran exagerados. Advertía que gracias a la nueva legislación la situación económica estaba mejorando; "El presente estado económico del país [...] es un estado transitorio", argüía con optimismo.

A fin de convencer a su audiencia de la verdad de sus advertencias, Dessús empleaba lenguaje fuerte, emotivo y a veces hiperbólico. Por ejemplo, imaginando el triste destino de los migrantes atrapados en el comercio de seres humanos, los describe como "fruto de mercado, objeto miserable de pregón y venta". Dessús terminaba el artículo advirtiendo a quienes contrataban a los trabajadores -quienes presumiblemente eran cristianos, como él mismo en aquel tiempo-que en el Juicio Final serían objeto de castigo:

22 Al respecto véase Luis Felipe Dessús, "Comentando. La próxima emigración". The Puerto Rico Eagle 22 Dec. 1903: 2.

23 Acerca del proyecto migratorio véanse Acosta y Santiago Puerto Ricans in the United States: A Contemporary Portrait (50-54), Whalen, "Colonialism, Citizenship, and the Making of the Puerto Rican Diaspora: An Introduction," (6-9), Ayala y Bernabé, Puerto Rico in the American Century: A History since 1898 (41) y Rodríguez-Silva, Silencing Race (149-150). 
[...] no olvidéis que la mano de Dios dejará caer sobre vuestras almas el peso de su terrible castigo, en la suprema hora de pruebas severísimas de las cuales no podéis escapar, como no escapa de la persecución y la pena, ningún pirata sin freno, sin religión y sin patria.

Las declaraciones de Dessús evidencian su sincera y clara preocupación por el bienestar de los puertorriqueños. Reconocía el daño económico, social y moral real que la emigración de trabajadores puertorriqueños significaba para el país: la pérdida de trabajadores capaces, el debilitamiento del orgullo y la confianza nacional, la ausencia de proveedores del sustento diario, el estrés emocional producto de la ausencia y la separación de los seres amados y la incertidumbre acerca del regreso de quienes migraban. Impregnado de un alto sentido de patriotismo, Dessús trataba de convencer a los trabajadores de la falsedad de las promesas y de las esperanzas que pregonaban los contratantes de mano de obra migrante: "La emigración es un suicidio, precedido de una nostalgia profunda, y una desesperación mortal", decía tanto a los potenciales migrantes como a los lectores. A la vez que mostraba simpatía por los trabajadores que ansiaban desesperadamente mejorar su situación económica, no escatimaba su más severa crítica a los "mercaderes del hombre" a quienes mostraba como traidores a sus paisanos: "traficadores en su obra inhumana de traficar vidas y libertades ajenas con la traición y con el engaño", pues inducían a los trabajadores a abandonar su patria, su familia y su hogar.

Con estos y otros agudos artículos de prensa publicados durante la primera década del siglo XX, Dessús sin duda logró el reconocimiento como periodista valiente, duro, iconoclasta. En años posteriores escribiría ensayos, artículos y poemas que tratarían temas delicados como la raza, contraviniendo la visión estandarizada y llevándolo cerca de una posición herética, no muy lejana de aquella de los race men afroamericanos cuyos escritos él leía y traducía ${ }^{24}$.

Aunque ningún artículo publicado por Dessús en el periodo comprendido entre 1907 y 1916 ha sido encontrado aún por los investigadores, en el libro Flores y balas

24 He tomado el término hereje del libro Black Heretics, Black Prophets: Radical Political Intellectuals de Anthony Bogues, para quien la herejía dentro de la tradición radical negra implica "un desafío a la ortodoxia [...] significa volverse humano, no blanco o imitación de quien detentaba el poder colonial, sino un claro subvertir la normatividad blanca/europea". Al hacerlo "se crea un nuevo discurso crítico" (13). Uno de los intelectuales a quienes Bogues identifica como hereje es W. E. B. Du Bois. Dessús conocía los escritos de Du Bois que habían sido publicados en The Crisis Magazine (fundada en 1910), órgano de la National Association for the Advancement of Colored People (NAACP), y luego también con los editoriales de Cyril V. Briggs, fundador de la Crusader Magazine (1918-1923) y de la African Blood Brotherhood. 
(estados de alma), se encuentra información útil para apreciar la constancia y el desarrollo de las ideas y principios del escritor ${ }^{25}$. La parte final del libro contiene catorce textos en prosa, todos con fecha. El más temprano es "Sueños rojos", fechado en julio de 1907, escrito durante su encarcelamiento. De los restantes, dos fueron escritos en 1913 ("El periodista y el pueblo"y "El gran monstruo"), cinco en 1915 ("Civismo que declina. El peligro del sufragio universal", "Voz de alarma", "Alrededor de la vida", "El terrible Marat" y "Cristo irredentor. Booker T. Washington") y seis en 1916 ("Al pie del suicidio", "Con el brazo", "Mulatismo", El día de las madres", "Dos tendencias. Pan americanismo - Hispano-americanismo" y "Ultima verba"). Estos artículos dejan ver las opiniones y sentimientos del autor sobre asuntos como la lucha por la libertad, la obligación de resistir a la depresión y a la derrota, el papel del periodismo en las luchas populares y el recuerdo/lamento por la madre ausente.

El ensayo "Mulatismo", escrito en julio de 1916, refleja el desarrollo del discurso crítico de Dessús en los asuntos relacionados con la raza y la nación. Estos aspectos serán analizados a continuación. Dedicado al escritor, político e intelectual negro Tomás Carrión Maduro (1870-1920), también nacido como Dessús en Juana Díaz, "Mulatismo" condena la actitud y conducta de la aristocracia criolla mulata que ni recuerda ni se identifica con sus orígenes negros. Dessús afirma que los puertorriqueños son una "sub raza" nacida de la mezcla violenta entre europeos, amerindios y africanos, ocasionada por la conquista, la trata de esclavos y la esclavitud y la subsiguiente mezcla de los descendientes de quienes llegaron a América. De la mezcla salieron quienes lucharon por la independencia en América Latina ("la legión libertadora de América" 200) y el pueblo puertorriqueño. Al afirmar "somos humanidad", Dessús insiste en que los puertorriqueños no deben avergonzarse de su linaje. Sin embargo, señala que algunos "mulatos de pigmento más o menos claro y de crencha más o menos ruda [...] han caído en la necedad de creerse blancos de pura raza" (200). Es más, Dessús arguye, puesto que personas de todas las clases se enorgullecen de entrar en "las salas de nuestros aristocráticos", sean dirigidos por "los autorizados por su talento, cultura o posición financiera" o por "cuadrumanos sin espíritu y sin preparación cultural para ser fuerzas directoras de una sociedad", existe en Puerto Rico, "desdichadamente, una aristocracia mediocre, plena de pauperismo intelectual" (201) y desprovisto de discernimiento alguno.

25 El título del libro pudo haberse inspirado en los siguientes versos del poema "A Cuba" escrito por la poeta puertorriqueña Lola Rodríguez de Tió (1843-1924) e incluído en su colección Mi libro de Cuba (Havana, Cuba: La Moderna, 1893): "Cuba y Puerto Rico son / de un pájaro las dos alas / reciben flores o balas / sobre el mismo corazón". 
Dessús señala que las diferencias políticas representan un obstáculo para la formación de la nación, pues ellas han llevado al sacrificio de grandes ideas y a la persecución y difamación de personas ilustres. Igualmente, las diferencias sociales han obstaculizado la formación de una verdadera sociedad puertorriqueña, la cual es, en su mayoría, controlada tanto política como culturalmente por los extranjeros. En efecto, afirma, lo extranjero triunfa. Es decir, que lo extranjero es lo que se impone entre la gente. Los europeos y los norteamericanos gozan en Puerto Rico, Dessús señala, de ciertos privilegios, lo que él atribuye a un espíritu de sumisión asociado al sentimiento de inferioridad que reside en la mentalidad criolla. De acuerdo con Dessús, un ejemplo de esta simpatía por lo extranjero es la preferencia que las jóvenes mujeres bellas, talentosas y de buena posición social y económica sienten por "cualquier patán aventurero fugado de Europa o de Estados Unidos, antes que a un criollo de buena cepa y de recomendables condiciones de sociabilidad y de cultura" $(201)^{26}$.

A diferencia de la verdadera aristocracia, advierte Dessús, la de Puerto Rico está aún en formación, dado que valora más el color de la persona que sus virtudes $^{27}$. La ausencia de personas de piel oscura entre las élites y la consiguiente abundancia de personas incultas, personas de razas mezcladas y de personas bastardas ${ }^{28}$ prueba aún más la falsedad o atraso de una aristocracia que discrimina a los negros, sin considerar sus logros profesionales y culturales. Aunque los criollos eran admitidos en los círculos aristocráticos controlados por la gente de origen español no tenían posiciones de autoridad ni gozaban de los privilegios de una pertenencia plena a la aristocracia (202). Sin embargo, los criollos eran quienes mantenían estos grupos.

Para Dessús, la danza puertorriqueña es la única expresión autóctona de la cultura puertorriqueña y se halla en peligro de desaparecer debido al avance de las danzas extranjeras. La falla de las élites, que no se enorgullecen de la cultura propia, impide que el país se convierta en pueblo social y moralmente organizado, es decir,

26 Jorge Juan y Antonio de Ulloa, dos funcionarios reales designados para escribir un informe sobre las colonias españolas en el siglo XVIII hicieron una observación similar. Véase $A$ Voyage to South America (32-33).

27 En 1878 el poeta colombiano Candelario Obeso también criticó la preocupación de la sociedad con lo superficial y la blancura: "El mérito de un hombre está en su alma [...]. La tradición de algunos es horrible, oscura como sus almas. Su conato es ser blancos y bonitos.... A mí me honra el ser negro i mi fealdad me encanta" (51, énfasis en el original). La cita de Dessús nos hace recordar las palabras del Dr. Martin Luther King,Jr. en su famoso discurso de la marcha sobre Washington en agosto de 1963: "Yo tengo el sueño de que mis cuatro pequeños hijos un día vivirán en una nación en la cual no serán juzgados por el color de su piel sino por su carácter" (104).

28 El texto dice: "abundan los bastardos, los mestizos y los iletrados" (202). 
una nación. Las clases altas, que deberían ser modelo para el desarrollo nacional carecen de conciencia y fuerza intelectual y adolecen especialmente de una vanidad que permea las otras clases, contaminándolas con los mismos vicios. Así, tal como los nativos de Puerto Rico muestran su preferencia por los extranjeros, algunas mulatas y hombres, sostiene Dessús, han internalizado la supremacía blanca, al punto de que una mujer mulata considera un honor ser amada por un blanco -aunque sea tosco e ignorante- y en el caso de los hombres darían con gusto su amor y fortuna a cualquier mujer, por inculta y fácil que ella sea ${ }^{29}$. Dessús insiste, sin embargo, en que cuando el amor reina las relaciones de blancos, negros y mulatos, sin distinción de clase, puede terminar en noviazgo y matrimonio.

En el siguiente tramo de su ensayo Dessús fija su atención directamente en los asuntos raciales. Sostiene que los "mulatos blanqueados" que son miembros de la élite muestran un mayor grado de solidaridad entre ellos y quizá hacia personas de piel oscura que los "grifos", cuyo disimulo y trivialidad muestran lo que ellos realmente $\operatorname{son}^{30}$. Dessús distingue a continuación la diferencia entre la conducta de "el lugareño blanco" y la del "lugareño negro del litoral". Cuando el primero va a la ciudad, se mezcla con las élites urbanas, escucha la música citadina y es deslumbrado por el refinamiento colorido y brillante y pierde su naturaleza humilde. Por otra parte, el lugareño negro, más acostumbrado a relacionarse con las gentes de ciudad, está por ende más preparado y socializa sin verse afectado por la ridiculez de los males de la sociedad puesto que no alberga ambición alguna y no permite que la envidia lo degrade (204). Dessús parece implicar que el fuerte sentido de identidad racial y cultural del lugareño negro del litoral lo protege de desvíos y por tanto, es fuente de desarrollo nacional y auto afirmación.

29 El texto dice: "Hay mulatas que aceptan como un honor ser amadas por un blanco, aunque sea un ignorante pendenciero, $y$ hay mulatos que le dan su nombre, su amor y su fortuna a una blanca, aunque sea una inculta casquivana" (203).

30 El texto dice: "Los mulatos blanqueados que informan nuestra aristocracia sostienen más el espíritu de solidaridad que los grifos cuya parejería e insignificancia los evidencia y ridiculiza". El término "mulato blanqueado" parece referirse a la persona mezcla de diversas razas aculturada quien a través de educación y oportunidades ha podido obtener las ventajas de las cuales disfruta la sociedad blanca, mejorando así su estatus social, cultural y económico. El término grifo se refiere a una persona descendiente de africanos, cuya piel es más clara y que con la excepción del pelo rizado, difícilmente tiene características asociadas a los negros. Manuel Alvarez Nazario señala: "Ser (una persona) un negro o un grifo parejero. [Es] expresión que se dice peyorativamente de la persona de color de quien se entiende que reclama o pretende trato a la par con otras gentes a quienes se considera superiores en la escala social" (361). Debe recordarse que el poeta Luis Palés Matos, amigo de Dessús, tituló su libro de poesía negrista Tun tun de pasa y grifería (1937), refiriéndose al sonido del tambor de negros y mulatos. 
Dessús culpa a los mulatos, a quienes describe como "semiletrados o ignorantes" (204), de mantener los graves errores que se encuentran en la base de la vida social nacional. Ve su arrogancia, vanidad e ignorancia sobre lo que constituye la verdadera sociabilidad, la irreal aspiración de grandeza, y otros factores como causantes de mantener la sociedad "en una justa inverosímil" (204). Sostiene que los puertorriqueños se preocupan por los asuntos relacionados con la raza, aunque la ciencia y la historia les hayan dado bases para conocer la verdad acerca de sí mismos. En consecuencia, ve a las futuras generaciones aún ocupadas de las mismas tareas dañinas y poco fructíferas, que desafían las leyes de la naturaleza que son equidad y razón. Dessús expresa su esperanza, sin embargo, en que la educación y la evolución política, impulsadas por la democracia, podrán superar "esa peligrosa enfermedad" (205) que es el asunto racial. Curiosamente, en estos escritos que se produjeron cuando la devastación y mortandad ocasionada por la Primera Guerra Mundial, Dessús afirma que la raza carece de influencia en la civilizada Europa en donde la humanidad viaja por caminos más ilustrados. Claramente, desde su punto de vista, los problemas de raza existentes en Puerto Rico no tienen un equivalente en Europa. En los años siguientes sin embargo, Dessús adoptaría una actitud más militante aunque matizada, a medida que comienza a abordar las luchas raciales de los afroamericanos. Como se analizará a continuación, su ensayo sobre Booker T. Washington muestra una perspectiva más amplia, que va más allá de Puerto Rico y refleja si no una visión panafricana, sí una perspectiva internacional.

Fechado en noviembre de 1915 "Cristo irredentor. Booker T. Washington" (Flores y balas 244-253) es una evaluación crítica de la filosofía del acomodo, la conciliación y tolerancia del complejo y controvertido vocero afroamericano, escrita poco después de su muerte ${ }^{31}$. Como el título sugiere, Dessús veía a Washington como a un Cristo que no se arrepiente que "acariciado por una inconcebible mansedumbre, pletórica de bondades y condescendencias" (248), era muy proclive a poner la otra mejilla. Mientras Dessús reconocía la labor educativa

31 Es interesante señalar que Eugenio Lecompte Benítez, a quien Dessús dedicó su poema "Quimeras", estudió con Washington en el Tuskegee Institute. Para más información, vease: http:// escinteugeniolecompte.blogspot.ca/2011/09/biografia-de-eugenio-le-compte-benitez.html. El poema fechado en junio de 1916, aparece en Flores y balas (41) y fue reproducido en el número del 5 de julio de 1919 de Pancho Ibero. En Forging Diaspora: Afro-Cubans and African Americans in a World of Empire and fim Crow Guridy estudia el papel que jugaron tanto Washington como el Tuskegee Institute en la educación de puertorriqueños y cubanos luego del retiro español de sus dos últimas colonias en América Latina. Lecompte, sin embargo, no es mencionado en el libro. 
que con jóvenes iletrados y sin esperanza adelantó Washington, mostrando a pesimistas e indolentes que con resolución, lo que una persona honorable y decidida podía lograr, también lamentaba que el autor de Up from Slavery no tuviera una posición más agresiva en solidaridad con otros letrados negros (248) ${ }^{32}$. Al recordar la crítica que distinguidos afroamericanos habían formulado a la posición que sobre la igualdad social tenía Washington y el viaje del educador a Europa, Dessús contrastaba la representación idílica que Washington supuestamente había dado a la prensa europea sobre la dura realidad de la segregación y la discriminación que afrontaba la gente negra a diario (249).

Dessús también mencionaba algunos incidentes ocurridos en la vida de Washington que servían para ilustrar las razones de la desfavorable opinión que los puertorriqueños tenían del líder negro (aunque algunos de esos incidentes eran erróneos). Por ejemplo, se refiere a la invitación que Washington recibió en octubre de 1901 "para almorzar" con el presidente Roosevelt en la Casa Blanca y la negativa de la empleada blanca a servirle la comida (249-250). Washington fue no solamente tratado con respeto sino que la comida no era un almuerzo sino una cena -una mejor ocasión que un almuerzo ${ }^{33}$. Dessús también recordó el asalto del que fue víctima Washington en Nueva York en marzo de 1911, a manos de un furioso blanco pobre quien lo acusó de ser un mirón y una persona que irrespetaba a su esposa (250) ${ }^{34}$. De acuerdo con Dessús, Washington salió en defensa de su agresor durante el juicio que se llevó a cabo en noviembre de ese año ${ }^{35}$. O sea que Dessús compartía la posición de quienes creían que Washington aceptaba el statu quo de injusticia, discriminación y violencia ejercida sobre los ciudadanos afroamericanos "sin protesta ni coraje" (246). De hecho, años después de su famoso discurso pronunciado en la Exposición de Atlanta de 1895, Washington continuó insistiendo en su enfoque acomodaticio sin perturbaciones::

32 Dessús cita la traducción al español de la autobiografía de Washington, titulada De esclavo a catedrático, publicada en 1902.

33 Para detalles acerca de la invitación, la cena y la reacción que provocaron, véase Severn y Rogers (306-318). El incidente recuerda el dicho empleado en Hispanoamérica: "Cuando un blanco está comiendo / con un negro en compañía, / el blanco le debe al negro / o es del negro la comida" (citado por Paulo de Carvalho-Neto) o, en otra versión, "Si ves a un negro comiendo/ de un blanco en compañía / o el blanco le debe al negro / o es del negro la comida". Dessús erróneamente recuerda la fecha del ataque como ocurrido "hace, próximamente dos años" (250).

35 Para detalles acerca del incidente, véase el artículo aparecido en el New York Times "White Man Assaults Booker Washington". Para un informe acerca del juicio y los comentarios de la prensa afroamericana, véanse los artículos publicados en The Goshen Weekly News-Times "Acquit Assailant of Mr. Washington. Ulrich Found Innocent by Special Sessions Justices and James Anderson", y el The New York Amsterdam News "An Editorial: A Miscarriage of Justice". 
Mucho mayor coraje se requiere para sufrir en silencio o para no levantarse cuando se invita a los disturbios. A larga es la raza o el individuo que resiste con mayor paciencia, dignidad y autocontrol, en medio de las peores condiciones el que se abre camino y obtiene el respeto del mundo ${ }^{36}$.

Al parecer, Dessús no tuvo conocimiento de los pronunciamientos públicos de Washington contra el tratamiento injusto, bárbaro e inhumano sufrido por los negros a manos de los blancos y de su esfuerzo encubierto para cambiar estas condiciones y proteger los derechos de los afroamericanos ${ }^{37}$. Como Dessús confesó: "No conozco la labor de Booker T. Washington, en el sentido de denunciar ante el mundo las mentiras de una constitución que no han sabido respetar ni el Estado, ni la sociedad americanas" (252).

Por contraste, Dessús sí conocía bien la importancia histórica del revolucionario haitiano Toussaint L"Ouverture (1743-1803), cuyo liderazgo heroico contra el ejército de Napoleón hizo a Dessús llamarlo "Libertario más fiero, guerrero más audaz y reparador más confiado en la fé (sic) de su propia causa" (251). El uso de la metáfora "corona de espinas" (252) para referir la traición francesa a Toussaint sugiere que Dessús lo veía como una figura Cristo más apropiada que Washington: "Preparar a un pueblo en la mansedumbre y educarlo en la humildad, es degenerarlo bruscamente, cerrándole el camino de su emancipación" (252), señaló. Al final, sin embargo, Dessús lamentaba la muerte de Washington porque, como escribió, "cuando se pierde una vida consagrada al estudio, al progreso y al bién (sic) de la humanidad, deben llorar todos los ojos, y conmoverse todos los corazones" (252-253).

Los escritos de Dessús examinados en este ensayo merecen ser leídos y estudiados. Su ensayo sobre Washington es particularmente valioso porque brinda una perspectiva escasa: aquella de un negro de las Antillas hispanohablantes que se pronuncia sobre el más celebrado y poderoso líder afroamericano de fines del siglo XIX y principios del XX. En un periodo en el cual el territorio en el que Dessús vivía había caído bajo el total dominio político y económico de los Estados Unidos -que se convertía en poder imperial,

36 Booker T. Washington, "Solving the Race Problem", publicado en The World (énfasís mío).

37 Por ejemplo, el 29 de febrero de 1904 The Birmingham Age-Herald publicó un artículo de Washington titulado "A Protest Against the Burning and Lynching of Negroes" (Una protesta contra la quema y el linchamiento de los negros), que también circuló en otros periódicos. Véase también el cuidadoso análisis que hace Louis Harlan de la "Politics of Accommodation" de Washington en Booker T. Washington in Perspective: Essays of Louis R. Harlan, edited by Raymond Smock (1988. Jackson, MS: University of Mississippi Press, 2006.164-179). 
no solo apropiándose de territorios habitados mayormente por gente de color sino institucionalizando la propuesta segregacionista continental "separados pero iguales" aplicada a las relaciones entre blancos y negros y que permitía la violencia contra la población negra-, afro-puertorriqueños como Dessús prestaban atención a la situación social y política de sus hermanos anglófonos cuya lucha descubría la hipocresía de la vida estadounidense y ponía de relieve la traición de sus ideales y principios democráticos.

Afro-puertorriqueños cultos, firmes, intelectualmente inquietos y radicalmente orgullosos como Dessús, Ramón Emeterio Betances, José Celso Barbosa, Tomás Carrión Maduro, Pedro C. Timothée y otros, por medio de viajes, educación y lecturas, se mantenían informados no solo de asuntos y condiciones en su país sino también en los Estados Unidos y en otros lugares, los cuales pudiesen afectar su sociedad o permitirles comprender mejor cómo resolver los problemas de su gente.

A diferencia de los blancos compatriotas suyos, los negros hispanohablantes sabían que aunque el lenguaje, la cultura y la religión los unían a los compatriotas blancos, la identidad racial (el color) no solo los separaba sino que también los unía a comunidades mayores también afrodescendientes que vivían en los Estados Unidos y otras partes. Los escritos de Dessús que se han analizado aquí nos ayudan a entender cómo durante un periodo clave de comienzos del siglo XX un dinámico, patriótico y comprometido intelectual afro puertorriqueño resistió, por medio de la palabra escrita, los esfuerzos por monopolizar el discurso nacionalista y por silenciar la expresión de la identidad racial. Revelan cómo un escritor negro intentó conciliar la lucha por alcanzar los ideales nacionalistas con la afirmación de conciencia racial, en una sociedad que se enorgullecía de su tolerancia racial y de su indiferencia ante el color de la piel en asuntos sociales y políticos mientras mantenía la supremacía blanca. En fin, Dessús se atrevió a presentar nuevas y poco ortodoxas perspectivas sobre la lucha de Puerto Rico por su liberación.

Este ensayo ha buscado mostrar el sentimiento nacionalista y la conciencia racial en algunas publicaciones del escritor y periodista afro - puertorriqueño Luis Felipe Dessús. No pretende agotar el tema pues el análisis de los escritos conocidos de este autor demanda más espacio y tiempo. Además se requiere mayor investigación para hallar otros escritos que puedan proporcionarnos un conocimiento a profundidad de sus ideas, especialmente las relacionadas con el espíritu nacionalista y la identidad racial. En futuros ensayos me propongo estudiar algunos poemas incluidos en Flores y balas y los artículos de la serie "La raza negra y la independencia de Puerto Rico" publicados por Dessús en su 
revista Pancho Ibero. Creo que tales pueden llevar a un mayor aprecio de los escritos de este poco conocido pero importante y singular escritor puertorriqueño de comienzos del siglo XX. También pueden, como espero lo haya hecho este trabajo, contribuir a la comprensión de la complejidad de los asuntos, de los retos y luchas que los puertorriqueños con puntos de vista políticos y proveniencias raciales diferentes debieron afrontar y proyectar.

\section{Obras citadas}

Acosta, José N. Propios y extraños. Colección de poesías.

Santurce, P.R.: Tipografía El Despertar, s.f.

Acosta-Belén, Edna, y Carlos E. Santiago. Puerto Ricans in the United States: A Contemporary Portrait. Boulder: Lynne Rienner Publishers, 2006.

-. Acquit Assailant of Mr. Washington. Ulrich Found Innocent by Special Sessions Justices". The Goshen Weekly News-Times. 10 Nov. $1911: 7$.

Álvarez Nazario, Manuel. El elemento afronegroide en el español de Puerto Rico: contribución al estudio del negro en América. 2a ed. revisada y aumentada. San Juan de Puerto Rico: Instituto de Cultura Puertorriqueña, 1974.

Anderson, Benedict. Imagined communities: Reflections on the Origin and Spread of Nationalism. Revised edition. Londres y Nueva York: Verso, 1991.

Anderson, James. "An Editorial: A Miscarriage of Justice". The New York Amsterdam News 11, Nov. 1911.

Ayala, César, y Rafael Bernabé. Puerto Rico in the American Century: A History since 1898. Chapel Hill: The University of North Carolina Press, 2007.

Belchem, John, y Richard Price, eds. The Penguin Dictionary of NineteenthCentury History. Londres: Penguin Books Ltd., 1996.

Bogues, Anthony. Black Heretics, Black Prophets: Radical Political Intellectuals. Nueva York: Routledge, 2003.

Briggs, Cyril V. "Race Catechism”. Crusader 1 (November 1918): 125-126. Brindis de Salas, Virginia. Cien cárceles de amor. Montevideo: Compañía impresora, 1949.

-. Pregón de marimorena (poemas). Montevideo: Sociedad Cultural Editora Indoamericana, 1947.

Carreras, Carlos N. Antología completa de poetas portorriqueños. Compilación y prólogo de Carlos N. Carreras. San Juan, P.R.: Puerto Rico Ilustrado, 1922. Disponible en http://books.google.ca/books?id=EdQvAQAAMAAJ\&q=Dessus\#search_anchor

Carvalho-Neto, Paulo de. El folklore de las luchas sociales; un ensayo de folklore y marxismo. México: Siglo Veintiuno Editores, 1973. 
Colección de las sentencias y resoluciones dictadas por el Tribunal Supremo de Puerto Rico. Puerto Rico. Supreme Court. San Juan, P.R.:

Bureau of Supplies, Printing, and Transportation, 1903-1912.

Colomban Rosario, José, y Justina Carrión. El negro: Haití-Estados Unidos-Puerto

Rico. San Juan, P.R.: Negociado de Materiales, Imprenta, y Transporte, 1940.

Colón López, Joaquín. Pioneros puertorriqueños en Nueva York:

1917-1947. Houston: Arte Público Press, 2002.

Cordasco, Francisco, comp. y ed. The Puerto Ricans, 1493-1973: A Chronology

\& Fact Book. Dobbs Ferry, NY: Oceana Publications, 1973.

Cyrus, Stanley, ed. El cuento negrista sudamericcano; antología.

Quito, Ecuador: Casa de la Cultura Ecuatoriana, 1973.

Decisiones de Puerto Rico reformatted from the original and including, Fallos y sentencias del Tribunal Supremo de Puerto Rico. Puerto Rico.

Supreme Court; Puerto Rico: Department of Justice, 1899.

Dessús, Luis Felipe. "El cinismo de ayer". La fusticia (1901, o3 de mayo).

—. "Comentando. La próxima emigración". The Puerto Rico Eagle (1903, 22 diciembre).

—. "El déspota yanki". The Puerto Rico Eagle (1903, 14 diciembre).

-. Flores y balas (estados de alma). Guayama, P.R.: Tipografía Unión Guayamesa, 1916.

—. "La raza de color y la Independencia de Puerto Rico". Pancho Ibero 37 (III) (23 de agosto 23 1919) - 61 (IV) (7 de febrero 1920).

Du Bois, W. E. Burghardt. "Let Us Reason Together".

The Crisis 18.5 (1919, septiembre): 231.

-. The Souls of Black Folk. Greenwich, Conn.: Fawcett Publications, 1968.

Escuela Intermedia Eugenio Le Compte Benitez. "Biografía de Eugenio

Lecompte Benítez". Disponible en http://escinteugeniolecompte. blogspot.ca/2011/o9/biografia-de-eugenio-le-compte-benitez.html

Fanon, Frantz. Black Skin, White Masks. Nueva York: Grove Press, 1967.

Garner, Steve. Whiteness; an Introduction. Londres; Nueva York: Routledge, 2007.

Gómez Tejera, Carmen, Ana María Losada y Jorge Luis Porras, eds.

Poesía puertorriqueña. México, D.F.: Editorial Orión, 1966.

Grosfoguel, Ramón. "The Divorce of Nationalist Discourses from the

Puerto Rican People: A Sociohistorical Perspective". Puerto Rican

Fam: Rethinking Colonialism and Nationalism. Ed. Negrón-Muntaner y

Grosfoguel. Minneapolis: University of Minnesota Press, 1997. 6o-63.

Guridy, Frank Andre. Forging Diaspora: Afro-Cubans and African Americans in a World of Empire and Fim Crow. Chapel Hill: University of North Carolina Press, 2010. 
Harlan, Louis J. "Politics of Accommodation". Booker T. Washington in Perspective: Essays of Louis R. Harlan. Ed. Raymond Smock. Jackson, MS: University of Mississippi Press, 2006. 164-179.

Hernández, Gaspar Octavio. Obras selectas. Compilación, introducción, notas y bibliografía de Octavio Augusto Hernández. Panamá: Ministerio de Educación, Dirección Nacional de Cultura, 1966.

Jackson, Richard L. The Black Image in Latin American Literature.

Albuquerque: University of New Mexico Prss, 1976.

-. Black Writers in Latin America. Albuquerque: University of New Mexico Press, 1979.

Janer, Zilkia. Puerto Rican Nation-Building Literature: Impossible

Romance. Gainesville: University Press of Florida, 2005.

Johnson, Lemuel A. "'Amo y espero': The Love Lyric, Virginia

Brindis de Salas, and the African-American Experience of the

New World". Afro-Hispanic Review 3.3 (1984): 19-29.

Juan, Jorge, y Antonio de Ulloa. A Voyage to South America. The John

Adams Translation. [abridged]. Nueva York: Knopf, 1964.

King, Martin Luther,Jr. I Have a Dream: Writings and Speeches that Changed the World.

Ed. James Melvin Washington. San Francisco, CA: Harper San Francisco, 1992.

Lefebre, Enrique. "Estudios críticos. Luis F. Dessús: Flores y balas". Puerto Rico Ilustrado 350 (1917, 6 de enero): s.p.

Lewis, Marvin A. Afro-Hispanic Poetry, 1940-1980: from slavery to Negritud in

South American Verse. Columbia: University of Missouri Press, 1984.

-.Afro-Uruguayan literature: post-colonial perspectives. Lewisburg: Bucknell

University Press; Londres; Cranbury, NJ: Associated University Press, 2003.

-. Treading the Ebony Path:Ideology and Violence in Contemporary Afro-

Colombian Prose Fiction. Columbia: University of Missouri Press, 1987.

Lloréns Torres, Luis. "Guayama. A Luis Dessuse [sic]". Sonetos sinfónicos.

San Juan de Puerto Rico: Cía. Editorial. Antillana, 1914.

-. Obras completas. Tomo I. San Juan de Puerto Rico:

Instituto de Cultura Puertorriqueña, 1973. 127.

López, Adalberto, ed. The Puerto Ricans: their History, Culture, and

Society. Cambridge, Mass: Schenkman Publishing Co, 1980.

Maglia, Graciela, ed. Si yo fuera tambó; poesía selecta de Candelario Obeso y forge

Artel. Edición crítica. Bogotá: Editorial Pontificia Universidad Javeriana, 2010.

Martínez Masdeu, Edgar. La crítica puertorriqueña y el modernismo en Puerto

Rico. San Juan, P.R.: Instituto de Cultura Puertorriqueña, 1977.

McCarthy, Eugene J. Dictionary of American Politics. Baltimore: Penguin Books, 1968. 
Mena de Lozano, Úrsula, y Ana Rosa Herrera Campillo, comps.

En honor a la verdad. Bogotá: MH consultar, 2009.

Mills Young, Carroll. "Virginia Brindis de Salas vs. Julio Guadalupe: A

Question of Authorship". Afro-Hispanic Review 12 (2, Fall 1993): 26-30.

Navarro-Rivera, Pablo. "The Imperial Enterprise and Educational Policies

in Colonial Puerto Rico". Colonial Crucible: Empire in the Making

of the Modern American State. Eds. Alfred W. McCoy y Francisco A.

Scarano. Madison: University of Wisconsin Press, 2009. 263-174

Negrón-Muntaner, Frances, y Ramón Grosfoguel, eds. Puerto Rican fam: Rethinking

Colonialism and Nationalism. Minneapolis: University of Minnesota Press, 1997.

Negrón-Portillo, Mariano. "Surviving Colonialism and Nationalism". Puerto

Rican fam: Rethinking Colonialism and Nationalism. Eds. Negrón-Muntaner

y Grosfoguel. Minneapolis: University of Minnesota Press, 1997· 39-56.

Obeso, Candelario. Cantos populares de mi tierra. Bogotá:

Prensas del Ministerio de Educación Nacional, 1950.

Ojeda, Martha. Nicomedes Santa Cruz: ecos de África en

Perú. Rochester, N.Y.: Tamesis, 2003.

Palés Matos, Luis. "Melancolía. Para un febril poeta:

Luis Felipe Dessús". La poesía de Luis

Palés Matos. Edición crítica. Ed. Mercedes López-Baralt. San Juan:

Editorial de la Universidad de Puerto Rico, 1995. 84.

-. Tun tun de pasa y grifería. Poemas afroantillanos. Biblioteca de Autores

Puertorriqueños. San Juan de Puerto Rico: Imp. Venezuela, 1937.

Pancho Ibero 26 (1919, 3 de junio)- (1920, 18 de sept.).

Paralitici,José (Che). "Imprisonment and Colonial

Domination, 1898-1958". Puerto Rico Under

Colonial Rule: Political Persecution and the Quest for Human Rights. Ed. Ramón

Bosque-Pérez y José Javier Colón Morera. Albany: SUNY Press, 2005. 67-80.

Pedreira, Antonio S. Bibliografía puertorriqueña (1493-

1930). Nueva York: Burt Franklin Reprints, 1974.

-. El periodismo en Puerto Rico. Obras completas. Tomo

V. Río Piedras: Editorial Edil, 1969.

Porto del Portillo, Raúl. "Efemérides colombianas".

Diario de la Costa 22 (Septiembre 1944): 4.

Prescott, Laurence E. Candelario Obeso y la iniciación de la poesía

negra en Colombia. Bogotá: Instituto Caro y Cuervo, 1985.

—. "“"Negro nacı": Voice and Authorship in Verses Attributed to

Candelario Obeso". Afro-Hispanic Review 12.1 (1993): 3-15. 
-. Without Hatreds or Fears: Forge Artel and the Struggle for Black Literary Expression in Colombia. Detroit: Wayne State University Press, 2000.

Ramos-Perea, Roberto, ed. Literatura puertorriqueña negra del siglo XIX escrita por negros: obras encontradas de Eleuterio Derkes, Manuel Alonso Pizarro y Fosé Ramos y Brans: antología de la literatura puertorriqueña negra escrita por negros, 1880-1920. Estudio preliminar, recopilación y notas de Roberto Ramos Perea. San Juan de Puerto Rico: Ateneo Puertorriqueño, 2009.

Rivera de Álvarez, Josefina. Diccionario de literatura puertorriqueña. México: Ediciones de La Torre, Universidad de Puerto Rico, 1955.

-. Diccionario de literatura puertorriqueña. 2. ed. Revisada, aumentada y puesta al día hasta 1967. 2 vols. San Juan de Puerto Rico: Instituto de Cultura Puertorriqueña, 1970-1979.

Rodríguez de Tió, Lola. Mi libro de Cuba. Habana, Cuba: Imp. La Moderna, 1893. Rodríguez Silva, Ileana. Silencing Race: Disentangling Blackness, Colonialism, and National Identities in Puerto Rico. Nueva York: Palgrave Macmillan, 2012. Severn, John K., y William Warren Rogers. "Theodore Roosevelt Entertains Booker T. Washington: Florida"s Reaction to the White House Dinner". The Florida Historical Quarterly 54·3 (Jan. 1976): 306-318.

Stephenson Watson, Sonja. "Nationalist Rhetoric and Suppression of Negritude: Literary Whiteness in Poems by Federico Escobar and Gaspar Octavio Hernández". Afro-Hispanic Review 29.1 (2010): 169-186.

Suárez Findlay, Eileen J. Imposing Decency: The Politics of Sexuality and Race in Puerto Rico,1870-1920. Durham: Duke University Press, 1999.

—. "The Looking Glass". The Crisis 16 (1, May 1918): 21.

Thomas, Lorrin. Puerto Rican Gitizen: History and Political Identity in TwentiethCentury New York City. Chicago: University of Chicago Press, 2010.

Torres Rivera, Enrique, ed. Parnaso puertorriqueño: antología esmerada mente seleccionada de los mejores poetas de Puerto Rico. Barcelona: Imp. Maucci, 1920.

Vincent, Theodore G., ed. Voices of a Black Nation: Political fournalism in the Harlem Renaissance. 1973. Trenton, N.J.: Africa World Press [1990].

Washington, Booker T. "A Protest Against the Burning and Lynching of Negroes". The Birmingham Age-Herald 29 Feb. 1904. Disponible en: http://www.btwsociety.org/library/articles/4.php.

-. De esclavo a catedrático; autobiografía de Booker T. Washington. Trad. Alfredo Elías y Pujol. Nueva York: D. Appleton y Compañía, editores, 1902. Disponible en: http://archive.org/stream/deesclavocatedroopujogoog\#page/ng/mode/2up

—. "Solving the Race Problem". The World 2 (Aug. 1903). Disponible en http://www.btwsociety.org/library/articles/3.php 
Whalen, Carmen Teresa. "Colonialism, Citizenship, and the Making of the Puerto Rican Diaspora: An Introduction". The Puerto Rican Diaspora: Historical Perspectives. Eds. Whalen y VásquezHernández. Philadelphia: Temple University Press, 2005. 1-42.

Whalen, Carmen Teresa, y Victor Vásquez-Hernández, eds. The Puerto Rican Diaspora: Historical Perspectives. Philadelphia: Temple University Press , 2005.

"White Man Assaults Booker Washington". New York Times (2o March 1911): 1-2. Disponible en http://query.nytimes.com/mem/archive-free/

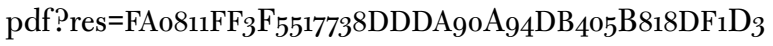

Zenón Cruz, Isabelo. Narciso descubre su trasero; el negro en la cultura puertorriqueña. $2^{\mathrm{a}}$. ed. 2 vols. Humacao, Puerto Rico: Editorial Furidi, 1975. 